\title{
Child Maltreatment
}

http://cmx.sagepub.com/

\section{Dyadic Profiles of Parental Disciplinary Behavior and Links With Parenting Context Jinseok Kim, Shawna J. Lee, Catherine A. Taylor and Neil Guterman Child Maltreat 2014 19: 79 originally published online 17 April 2014 \\ DOI: $10.1177 / 1077559514532009$}

The online version of this article can be found at:

http://cmx.sagepub.com/content/19/2/79

\author{
Published by: \\ (\$) SAGE \\ http://www.sagepublications.com \\ On behalf of:

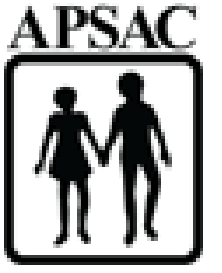 \\ American Professional Society on the Abuse of Children \\ Email Alerts: http://cmx.sagepub.com/cgi/alerts \\ Subscriptions: http://cmx.sagepub.com/subscriptions \\ Reprints: http://www.sagepub.com/journalsReprints.nav \\ Permissions: http://www.sagepub.com/journalsPermissions.nav \\ Citations: http://cmx.sagepub.com/content/19/2/79.refs.html \\ >> Version of Record - Jun 27, 2014 \\ OnlineFirst Version of Record - Apr 17, 2014 \\ What is This?
}

Additional services and information for Child Maltreatment can be found at: 


\title{
Dyadic Profiles of Parental Disciplinary Behavior and Links With Parenting Context
}

\author{
Jinseok Kim', Shawna J. Lee ${ }^{2}$, Catherine A. Taylor ${ }^{3}$, \\ and Neil Guterman ${ }^{4}$
}

\begin{abstract}
Using data from couples $(N=1,195)$ who participated in a large community-based study of families, we used maternal reports of parental discipline to examine mothers' and fathers' use of and patterns related to aggressive and nonviolent discipline of their 3year-old child. First, we separately examined mothers' and fathers' patterns, or classes, of disciplinary behaviors. Second, we identified joint mother-father class profiles. Maternal reports indicated that the patterns among fathers and mothers were similar, but fathers were more likely to be in the low-aggression classes than mothers; and mothers were more likely to be in the highaggression classes than fathers. Dyads in which both parents employed high levels of aggressive discipline were characterized by higher parenting stress, poorer parental relationship, and lower quality community context. The majority (8I.2\%) of dyads used congruent disciplinary behaviors. Discordant dyads were similar to dyads in which both parents were high in aggressive discipline, in that these groups had children with the highest levels of aggressive behavior. Implications highlight the need to target both mothers and fathers with parent education efforts to reinforce positive parenting.
\end{abstract}

\section{Keywords}

aggressive behavior, child maltreatment, community samples, fathers, latent profile analysis

Theories of family functioning stress the interdependence of relationships within families (Cox \& Paley, 1997). Children share a parenting context and thus are jointly influenced by their mothers and fathers. The developmental-ecological framework (Bronfenbrenner, 1979) in particular highlights how proximal relationships within the family system, such as parent-to-child or parent-to-parent interactions, and distal factors, such as those measuring community social disorganization and collective efficacy, influence risk for maltreatment (Belsky, 1993). For example, interparental violence (or IPV) increases risk for child maltreatment (Taylor, Guterman, Lee, \& Rathouz, 2009); and the potential influence of IPV may be heightened for families experiencing high levels of stress (Margolin \& Gordis, 2003) and among immigrant families (Taylor et al., 2009). Yet, despite the centrality of the coparenting relationship within the developmental-ecological framework, few studies of maltreatment have examined mothers and fathers as couples or considered the degree to which mothers' and fathers' disciplinary behaviors toward their young children may overlap or be distinct.

A main goal of this study was a preliminary examination of these issues using mother's reports of their own and their partners' use of discipline toward their young child in a sample of married or cohabiting parents. Research has shown that physical punishment, including spanking or hitting a child with an object or a stick, increases risk for child maltreatment (Lee, Grogan-Kaylor, \& Berger, 2014; Straus, Hamby, Finkelhor, Moore, \& Runyan, 1998; Zolotor, Theodore, Chang, Berkoff, \& Runyan, 2008). Belsky (1993) suggests that not only the greater use of physical discipline but also the absence of positive interaction such as parental inductive or reasoning behaviors may contribute to maltreatment. Indeed, it is important to consider aggressive and nonaggressive parenting in tandem because these behaviors are not orthogonal and studies show that physical punishment and other forms of aggressive discipline often occur in the context of parental warmth (Deater-Deckard et al., 2011; Lee, Altschul, \& Gershoff, 2013) or nonviolent discipline, such as time-out (Lee, Kim, Taylor, \& Perron, 2011). We assessed maternal report of their own and their partners' disciplinary behaviors and examined

\footnotetext{
' Seoul Women's University, Seoul, Korea

${ }^{2}$ University of Michigan, Ann Arbor, MI, USA

${ }^{3}$ Tulane University, New Orleans, LA, USA

${ }^{4}$ University of Chicago, Chicago, IL, USA

Corresponding Author:

Jinseok Kim, Seoul Women's University, Rm \#72I, Inmoonsawhoi-Kwan Bldg., 621 Hwarangno, Kongneung 2dong, Nowon, Seoul, Korea.

Email: jskim@swu.ac.kr
} 
the extent to which nonviolent behaviors may co-occur or be distinct from parents' aggressive discipline.

We utilized a latent profile analysis approach that allowed careful examination of the parenting subsystem based on both parents' discipline toward their 3-year-old child. Building from the developmental-ecological framework, we examined how dyadic disciplinary behavior profiles were linked to the ecology of the home environment, including parental relationship quality, child behavioral problems, and community context factors. In doing so, our research provides a first step in addressing (1) how mothers and fathers differ or are similar in their discipline of young children, (2) how parental disciplinary behavior profiles relate to measures associated with maltreatment risk factors across the developmental-ecological framework, and (3) whether discordant or concordant disciplinary styles are associated with child behavior problems. We focus on 3-year-olds because parental physical punishment, like spanking, peaks around this age (Straus \& Stewart, 1999), and young children and toddlers are at heightened vulnerability for maltreatment and abuse (Klein \& Harden, 2011).

\section{Mothers' and Fathers' Parenting Behaviors of Young Children}

There are a number of reasons to examine both mothers' and fathers' parenting behaviors. In studies based on parents' self-report, mothers' and fathers' parenting behaviors have distinct effects on their children's outcomes when their respective parenting influences are taken into account (Stolz, Barber, \& Olsen, 2005). For example, fathers', but not mothers', higher levels of permissive discipline, in which parents make few demands on their children and do not consistently impose rules or discipline, are associated with preschool children's increased externalizing behaviors (Jewell, Krohn, Scott, Carlton, \& Meinz, 2008). Similar to research with mothers (Taylor, Manganello, Lee, \& Rice, 2010), paternal physical punishment was associated with increased child aggression in preschool (Lee, Taylor, Altschul, \& Rice, 2013) and adolescence (Prinzie, Onghena, \& Hellinckx, 2006). Fathers' parenting influences extend to children's cognitive domains, with studies showing that fathers' warmth and stimulating parenting predicted enhanced academic outcomes for children, whereas fathers' restrictive discipline predicted lower academic skills (Coley, Lewin-Bizan, \& Carrano, 2011).

In the maltreatment literature, few studies have assessed the range of disciplinary tactics that children may be exposed to from mothers and fathers even though some prior research suggests that mothers and fathers spank young children at comparable rates (Day, Peterson, \& McCracken, 1998; Straus \& Stewart, 1999). As a result, prior research may underestimate children's exposure to discipline. In addition, few prior studies have examined mothers' perceptions of whether mothers and fathers differ in their use of nonviolent discipline. Thus, examination of both parents may more fully explain potential variation in maltreatment risk associated with mothers' and fathers' parenting behaviors.

Furthermore, little is known about discordant or concordant disciplinary styles within couples. Prior research has examined predictors of maternal and paternal physical and psychological aggression in separate models (Slep \& O'Leary, 2007). Other studies, which used observational methods as well as child report of parent behavior, indicate that mothers and fathers in couples tend to have similar levels of negative and supportive parenting (Martin, Ryan, \& Brooks-Gunn, 2007; Ryan, Martin, \& Brooks-Gunn, 2006; Simons \& Conger, 2007). However, while the majority of parents have complementary parenting styles, some do not (Simons \& Conger, 2007), and a small body of research points to the potential importance of discordant parenting styles. In one study, adolescents' adjustment scores were lowest when both parents (concordant) were high in authoritarianism or when fathers were permissive and mothers were authoritarian (discordant; McKinney \& Renk, 2008). Another study, using child report of parents' behavior, showed that child outcomes differed by how parental styles were combined. Results suggested that the unique clustering of parenting style within couples is important and that harsh or "authoritarian" parenting, even if it is experienced from one parent but not the other, may be related to negative outcomes for children (Simons \& Conger, 2007). These studies (McKinney \& Renk, 2008; Simons \& Conger, 2007) suggest that, rather than being driven by one parent's approach or behaviors, children's outcomes may vary due to the balance of parenting behaviors within couples. However, studies have focused on children's cognitive outcomes (Martin et al., 2007; Ryan et al., 2006) or adolescents (McKinney \& Renk, 2008; Simons \& Conger, 2007). We extend this research by examining how concordant or discordant parental discipline may relate to preschool-age children's behavioral problems, and we assess whether children may potentially be buffered from the negative effects of aggression from one parent when their parents have discordant disciplinary approaches, that is, one parent is characterized by high levels of aggressive discipline and the other parent is characterized by low levels of aggressive discipline.

\section{The Current Study}

This study was guided by three objectives. The first objective was to describe mothers' and fathers' disciplinary behavior patterns, or classes, of parental discipline toward their 3-year-old child. Our analyses should be considered a first step in part because our reliance on mothers' report of fathers' disciplinary behaviors, rather than fathers' self-report, may introduce measurement bias and inaccuracy in estimating fathers' behaviors. To determine disciplinary behavior patterns, or classes, we used latent class analysis (LCA), a person-centered analysis that seeks to determine whether unique or distinct homogenous classes exist within a heterogeneous data set (Muthen, 2001; Roesch, Villodas, \& Villodas, 2010). Based on mothers' 
assessments, we examined mothers' and fathers' disciplinary acts separately (first-order LCA) and jointly (second-order LCA). LCA provides a vantage point from which to understand distribution and variability in behaviors that are not orthogonal, for example, as discussed previously, parents who spank their children but who may also use acts of nonviolent discipline (Lee, Kim, Taylor, \& Perron, 2011) or be warm and responsive (Deater-Deckard et al., 2011; Lee, Altschul, \& Gershoff, 2013). We expected that a greater percentage of mothers than fathers will use all forms of discipline, because mothers spend more time caring for young children (Craig, 2006). We also hypothesized that the majority of couples would be congruent in disciplinary style.

The second objective built on the developmental-ecological model to examine parenting dyads and the parenting context. We hypothesized that parenting stress (Taylor et al., 2009) would be higher, and parental relationship quality would be lower, among the disciplinary classes characterized by high levels of parent-to-child aggression. Prior research demonstrates elevated risk for child behavioral problems among children who experience physical punishment (Taylor et al., 2010) or psychological abuse (Wang \& Kenny, 2013). Therefore, we hypothesized that behavior problems would be highest among those children who experienced the highest levels of parental aggression. We examined both externalizing and internalizing behavior problems because they reflect distinct biological temperamental predispositions that manifest in behavioral responses (anger and irritability, or inhibition and fearfulness) exacerbated by threatening environments, including those characterized by maternal harsh punishment (Sturge-Apple, Davies, Martin, Cicchetti, \& Henteges, 2012).

Additionally, a key tenet of the developmental-ecological framework is that neighborhood processes play a role in the etiology of child maltreatment (Coulton, Korbin, \& $\mathrm{Su}$, 1999). To address this aspect of the parenting context, we examined maternal perceptions of negative neighborhood processes, shown to influence parents' psychological distress and depression, which in turn predict harsh parenting and child behavior problems (Gutman, McLoyd, \& Tokoyawa, 2008; Kohen, Leventhal, Dahinten, \& McIntosh, 2005). Maternal perceptions of neighborhood processes may be related to maltreatment through indirect pathways, whereby more positive neighborhood processes are associated with lower parenting stress and greater personal control (Guterman, Lee, Taylor, \& Rathouz, 2009). We hypothesized that parental aggressive discipline would be associated with higher levels of negative neighborhood processes.

The third objective was to investigate parents' concordance in use of discipline. We examined whether children's behavior was associated with concordant high-aggression parenting or discordant parenting. Although our analyses were exploratory, we hypothesized that discordant behavior profiles and concordant high-aggression disciplinary behavior profiles would be similar to the extent that both would be associated with greater child behavioral problems when compared to concordant lowaggression parents.

\section{Method}

This study utilized data from the Fragile Families and Child Well-Being Study (FFCWS), a birth-cohort study following new parents and their children in 20 U.S. cities that oversampled nonmarital births at baseline (Reichman, Teitler, Garfinkel, \& McLanahan, 2001). Core interviews were conducted with mothers and fathers of 4,898 index children at the child's birth, with follow-up core interviews when the child was 1, 3, and 5 years of age. An add-on study, called the In-Home Longitudinal Study of Pre-School Aged Children, included mothers' report of child behavior, community context variables, and aggressive parenting behaviors of both parents. The In-Home study was conducted with a subset of mothers only; fathers were not included. Verbal and written informed consent was obtained from participants at each interview, and all respondents were informed of the interviewers' obligation to report observations of child abuse. A detailed description of the sampling strategy and related issues can be found in Reichman, Teitler, Garfinkel, and McLanahan (2001).

\section{Participants}

This study included married or cohabiting mothers and fathers who were both residing in the home at the time of the FFCWS 3 -year core interviews $(N=1,414)$. A large number of FFCWS parents did not meet our study criteria of being married or cohabiting at the 3-year interviews and thus were not included in our sample. We excluded couples with incomplete information from the fathers' 3-year core interview $(N=95)$, incomplete information from the In-Home study $(N=81)$, or incomplete information from the mothers' 3-year core interview $(N=43)$, resulting in a subsample of 1,195 couples for analysis.

All couples $(N=1,195)$ were married $(61.9 \%)$ or cohabiting (39.1\%). The majority of mothers $(35.2 \%)$ and fathers $(37.7 \%)$ were African American, followed by White-Caucasian $(32.8 \%$ of mothers; $31.1 \%$ of fathers), Hispanic (26.9\% of mothers; $26.6 \%$ of fathers), or other race/ethnic group (5.1\% of mothers; $4.7 \%$ of fathers). Average age of mothers and fathers at the time of the child's birth was 26.7 and 29.1 years, respectively. Almost half of the mothers $(47.7 \%)$ and fathers $(45.6 \%)$ had some college experience or higher education, $27.4 \%$ of mothers and $30.4 \%$ of fathers had a general equivalency diploma or high school diploma, and $25.0 \%$ of mothers and $24.0 \%$ of fathers had less than a high school degree.

\section{Measures}

All study measures were assessed when the index child was 3 years old. Measures of mothers' and fathers' discipline of the child, child behavioral problems, and perceived community processes were based on mothers' report during the 3-year In-Home study interview. Mothers and fathers self-reported parenting stress, perceived support from spouse, relationship quality, and psychological aggression during the 3-year core interview. 
Table I. Descriptive Summary of Parent-Child Conflict Tactics Scale Items.

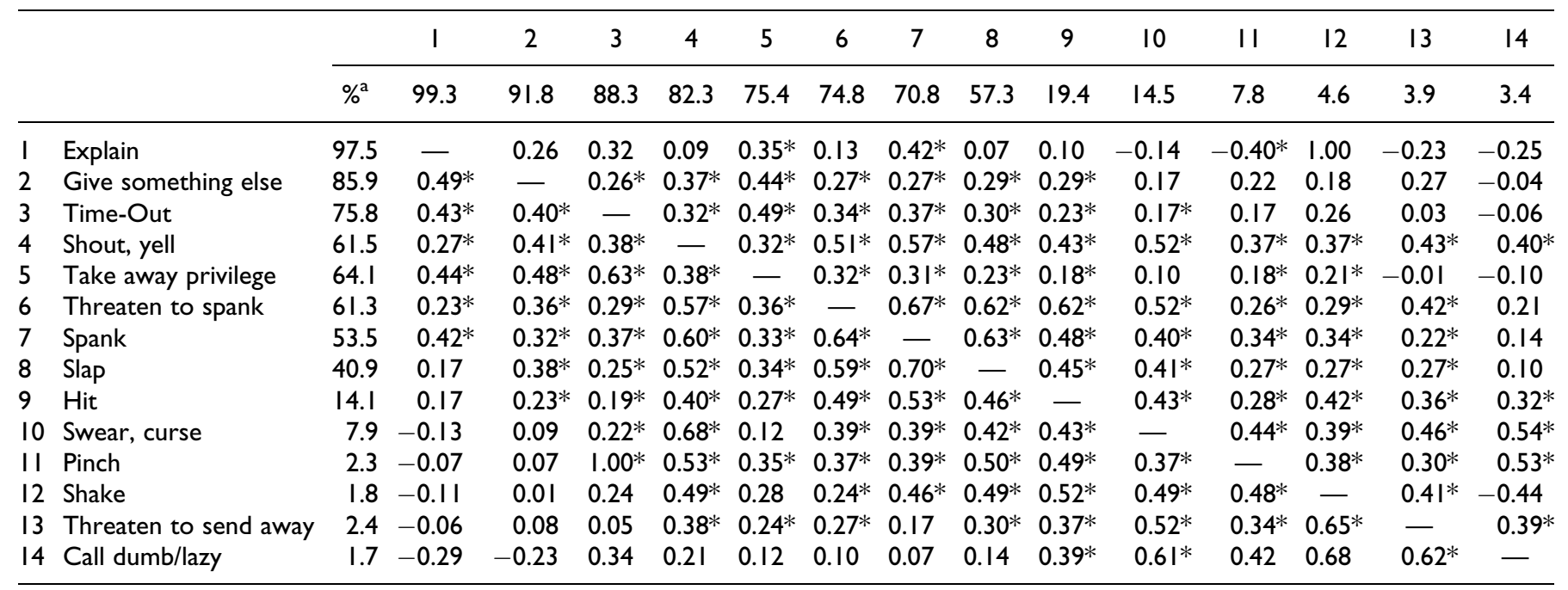

Note. Tetrachoric correlation coefficients are presented; Numbers above the diagonal are for mothers and numbers below the diagonal are for Fathers. ${ }^{\text {Percen- }}$ tage of mothers and fathers who used a CTSPC behavior at least once in the past year. $*_{p}<.05$.

Parental disciplinary behavior. Maternal report of the ParentChild Conflict Tactics Scales (CTSPC; Straus et al., 1998) measured whether in the past 12 months the mother or father utilized specific disciplinary behaviors $(0=$ absent, $1=$ present). Table 1 lists all 14 items analyzed in the LCA model. The use of a dichotomous variable is appropriate for the LCA (Roesch et al., 2010) and is recommended for nonclinical populations because of the skewed distribution of some CTSPC items (Straus, 2004; Straus et al., 1998).

Child behavioral problems. Child Behavior Checklist 1.5-5 (CBCL 1.5-5; Achenbach \& Rescorla, 2000) aggressive behavior, depressed/anxious behavior, and withdrawn behavior subscales measured child behavior problems, as reported by mothers during the In-Home interview. The same response scale $(0=$ not true, $1=$ somewhat or sometimes true, $2=$ very true or often true) was used for each subscale. For aggressive behavior (19 items; $\alpha=.87$ ), items included (child) is defiant, is demanding, and destroys others' things. For anxious/ depressed behavior ( 8 items, $\alpha=.63$ ), items included: [child] clings to adults, feelings hurt easily, and looks unhappy. For withdrawn behavior ( 8 items, $\alpha=.67$ ), items included: [child] avoids eye contact and shows little affection.

Parenting stress index-short form (PSI-SF). Parenting stress was measured using 4 items from the Parental Distress Subscale of PSI-SF (Abidin, 1995). Mothers and fathers reported their agreement ( 1 = strongly agree to $4=$ strongly disagree $)$ with questions such as "Being a parent is harder than I thought it would be" $\left(\alpha_{\text {mothers }}=.73 ; \alpha_{\text {fathers }}=.95\right)$. Responses were reverse scored such that higher scores indicate greater parenting stress.

Perceived support from spouse. Mothers and fathers reported their agreement with 6 items measuring how often the other parent expressed support ( $3=$ often, $2=$ sometimes, and $1=$ never $)$. Items included: "She/he is fair and willing to compromise when you have a disagreement" $\left(\alpha_{\text {mothers }}=.77 ; \alpha_{\text {fathers }}=\right.$ .68). Responses were reverse scored such that higher scores indicate greater perceived support.

Relationship quality. Mothers and fathers reported relationship quality using two questions. The first question asked, "In general, would you say that your relationship with him or her is excellent, very good, good, fair, or poor?" This item was scored so higher scores indicate greater relationship quality. The second question asked, "How often do you and [father/ mother] argue about things that are important to you?" (1 = Never to $5=$ Always).

Psychological aggression. Mothers and fathers reported psychological aggression using 4 items adapted from the Spouse Observation Checklist (Weiss \& Margolin, 1977). Items included: [Child's father/mother] "tries to keep you from seeing or talking with your friends or family" and [Child's father/mother] "tries to prevent you from going to work or school." A binary variable $(0=n o, 1=y e s)$ was constructed to indicate whether the mother or the father had experienced any of these forms of psychological aggression.

Community context. Three scales were used to measure maternal perceived community processes. First, collective efficacy (Sampson, Raudenbush, \& Earls, 1997; $\alpha=$.87) was measured using 5 items assessing informal social control and 5 items assessing social cohesion. Mothers indicated how likely they thought residents in their neighborhood would intervene in a series of situations such as "children skipping school and hanging out on a street corner," or mothers' agreement with statements such as "people around here are willing to help their 
neighbors." Higher scores indicate higher levels of collective efficacy. Social disorganization (Coulton et al., 1999; $\alpha=$ .93) was measured using 8 items that asked mothers how often the following took place in their neighborhood such as "drug dealers or users hanging around," "drunks hanging around," and "disorderly or misbehaving groups of teenagers." Higher scores indicate higher levels of social disorganization. Community violence (Selner-O'Hagan, Kindlon, Buka, Raudenbush, \& Earls, 1998; $\alpha=.75$ ) was measured using 7 items to indicate how often $(0=$ never to $4=$ more than 10 times $)$ mothers were exposed to violence carried out by people outside of their circle of loved ones, such as how often they saw someone "get hit, slapped, punched, or beaten up." Higher scores indicate more community violence.

\section{Analysis Plan}

Step 1: First-order LCA of mothers and fathers disciplinary behaviors in separate models. First, we analyzed the CTSPC items to identify independent latent profiles of mothers' and fathers' disciplinary behaviors. The model parameters were free to vary for both mothers' and fathers' models, and we examined number of classes and overall model structure in terms of posterior probability of each model. The empirical model fit was assessed using Bayesian information criterion (BIC), entropy, and Lo-Mendell-Rubin likelihood ratio test (Lo, Mendell, \& Rubin, 2001). In addition, the conceptual fit of the model was considered by examining the LCA results, model diagnostics, and a visual representation of the disciplinary styles.

Step 2: Single LCA of mothers and fathers with measurement model invariance constraints. We examined whether the identified disciplinary behavior profiles of mothers and fathers were similar or different. Thompson and Green (2006) suggest a procedure for assessing between-group differences in factor means of a continuous latent variable. We imposed a series of constraints on the models identified in Step 1 in terms of the number of classes (structural equivalence test), probability of endorsing individual CTSPC items (measurement equivalence test), and relative proportions of classes (factor/ class mean equivalence test). The test of these constraints was conducted using likelihood ratio $\chi^{2}$ tests and comparison of other model fit indexes such as BIC and Akaike information criterion between the models with and without the constraints.

Step 3: Joint (second order) LCA of mothers and fathers with measurement invariance constraints. In this step, the firstorder LCA model solutions identified separately for mothers and fathers in Step 2 were subjected to a second-order LCA of joint disciplinary behaviors. Conceptually, the second-order LCA seeks to identify dyadic mother-father patterns to show potential interdependence of parents' disciplinary styles. Analytically, this approach is similar to a second-order confirmatory factor analysis.
Step 4: Validation of the second-order LCA model. We examined the association between dyadic class membership and variables guided by relevant literature. LCA subgroups may be validated if theoretically predicted relationships are empirically observed. For example, correlation between parental relationship quality and LCA parenting dyads' use of parent-to-child aggression would show associations that would be expected based on the extant literature.

\section{Results}

Table 1 presents a descriptive summary of the CTSPC items and bivariate correlations among the items. Spanking and slapping were the two most common types of physical aggression for both mothers and fathers. Overall, more mothers reported that they used aggressive discipline such as spanking, $\chi^{2}(3$, $N=1,195)=308.1, p<.001$; hitting, $\chi^{2}(3, N=1,195)=$ 501.0, $p<.001$; or slapping, $\chi^{2}(3, N=1,195)=393.2, p<$ .001 , than they reported their partner used the same. For some items, the CTSPC yearly prevalence rates observed in Straus, Hamby, Finkelhor, Moore, and Runyan's (1998) nationally representative study of U.S. households were quite similar to those observed in the current study. For example, among mothers in the current study, $19.4 \%$ hit their child and $82.3 \%$ shouted or yelled at their child, compared to $20.7 \%$ and $84.7 \%$ (respectively) of the respondents in Straus and colleagues' study. However, slapping was more common in the current study, with $57.3 \%$ of mothers saying they had slapped their child, compared to $36.9 \%$ in Straus et al. For the most serious form of physical aggression, nearly $5 \%$ of mothers said they had shaken their child, compared to $9 \%$ in Straus and colleagues' study. For the most serious form of verbal aggression, only $3.4 \%$ of the mothers in the current study had called their child dumb or lazy or some other name like that, compared to $16.3 \%$ of the parents in Straus and colleagues' (1998) study. These differences may be due to the fact that physical aggression toward toddlers is more common than verbal aggression (Straus \& Stewart, 1999), and our study included parents of 3 -year-olds, whereas Straus et al. included parents of any child under age 18.

\section{Model Fit for First-Order LCA Classes}

Step 1 identified different four-class LCA models of disciplinary behavior, one for mothers and the other for fathers. Because the same number of classes was identified for mothers and fathers, three models with different levels of model constraints were compared with each other in Step 2. In the first model, no constraints were imposed on probabilities of endorsing class indicators (i.e., CTSPC items), given an LCA model or relative proportion of class membership (i.e., factor mean), hence a free model. The second model assumed that mothers' probability of endorsing a specific class indicator would be the same as fathers' if they were in the same class and that relative 


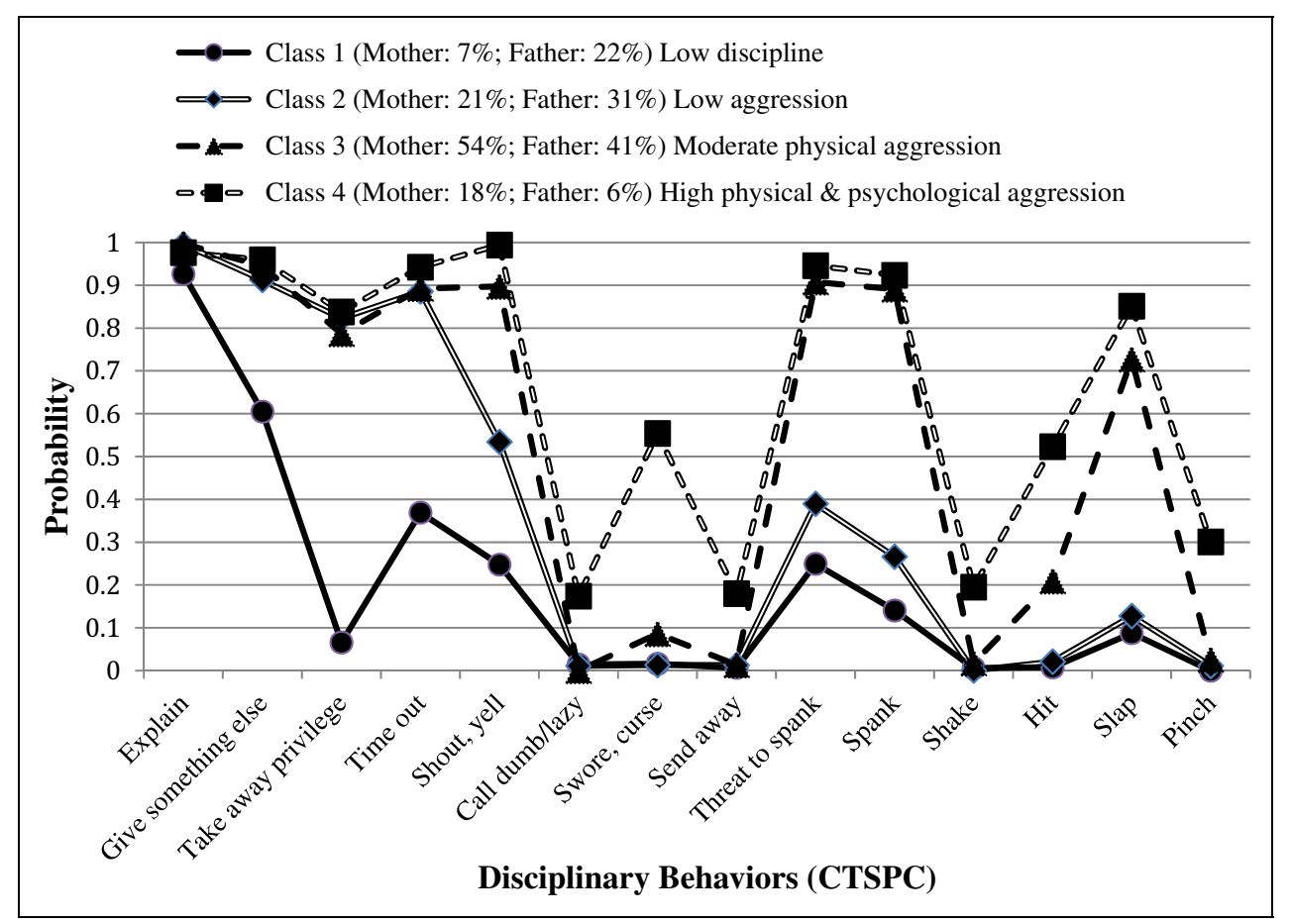

Figure I. Parents' probability of engaging in disciplinary behaviors based on LCA model with measurement invariance constraint. Note. LCA = latent class analysis.

proportion of class membership among mothers could be different from the same among fathers, hence an endorsement probability invariance model. The last model assumed no difference between mothers and fathers in terms of probability of endorsing a specific class indicator in a same class or a relative proportion of class membership, hence an endorsement probability and class proportion invariance model. Steps 1 and 2 of the previously described analysis procedure resulted in an endorsement probability invariance model with four distinct classes of mothers and fathers based on their parenting behaviors, which confirmed that, when examined separately, the mother and father disciplinary style group would be similar with each other in type and nature but not in proportional distribution across different style groups.

We examined a set of model fit statistics to decide the best fitting models among free, an endorsement probability invariance, and an endorsement probability and class proportion invariance models. While a free model without any constraints appeared to fit better than an endorsement probability invariance model based on a likelihood ratio test, $\chi^{2}(56, N=$ $1,195)=119.7, p<.001, \mathrm{BIC}$, and sample size adjusted BIC values of the free model $(\mathrm{BIC}=23,487.3$; adjusted $\mathrm{BIC}=$ $23,112.5)$ worsened when compared to the endorsement probability invariance model $(\mathrm{BIC}=23,209.0$; adjusted $\mathrm{BIC}=$ 23,012.0).A model with an endorsement probability and a class proportion invariance model appeared worse in terms of a likelihood ratio test, $\left.\chi^{2}(3, N=1,195)=221.2, p<.001\right)$, BIC $(=23,347.1)$, and a sample size-adjusted BIC $(=23,159.7)$ than an endorsement probability invariance model.
Figure 1 summarizes the parenting profiles based on the measurement invariance LCA model of mothers' and fathers' behaviors. The following labels describe the disciplinary behavior profiles: Low Discipline (LD, Class 1), Low Aggression (LA (Class 2), Moderate Physical Aggression (MPA, Class 3), and High Physical and Psychological Aggression (HPPA, Class 4). As seen in the figure, parents in the LA, MPA, and HPPA groups did not differ greatly in their use of nonviolent discipline. More detailed description of these first-order disciplinary behavior profiles may be found in Lee and colleagues (2011).

\section{Model Fit for Second-Order LCA Classes}

Given the measurement invariant LCA models of parenting behaviors of mothers and fathers, the second-order LCA model was calculated. All of the indices indicate that the four-class second-order LCA model as best fitting (Table 2). Table 3 summarizes the second-order LCA results. Class 1 was characterized by mothers using moderate level of physical aggression (MPA) and fathers using moderate or low aggression (MPA or LA). Class 2 was characterized primarily by mothers from any discipline group (LD, MPA, LA, or HPPA) combined with fathers with low levels of discipline (LD). Mother and father couples in Class 3 have highly congruent disciplinary styles with each employing low aggression (LA) strategies. Class 4 has the highest level of aggressive discipline. Mothers in this class use both high physical and psychological aggression (HPPA) and fathers have either moderate physical aggression (MPA) or high physical and psychological aggression (HPPA). 
Table 2. Fit Indices of LCA Models With Six Second-Order Class Models.

\begin{tabular}{|c|c|c|c|c|c|c|c|c|c|}
\hline & $\mathrm{LL}(\mathrm{H} 0)$ & Scaling factor & \# of free parameters & $\mathrm{AIC}$ & $\mathrm{BIC}$ & Adj. BIC & Pearson $\chi^{2}$ & $\operatorname{LR} \chi^{2}$ & Entropy \\
\hline 2 classes & -11138.1 & 1.332 & 69 & $224 \mid 4.1$ & 22765.0 & 22545.9 & 12544.6 & 3470.6 & 0.747 \\
\hline 4 classes & -10972.3 & 1.068 & 83 & 22110.5 & 22532.7 & 22269.0 & 12269.3 & 3361.3 & 0.854 \\
\hline 5 classes & -10972.3 & 0.987 & 90 & 22124.5 & 22582.3 & 22296.4 & 12269.3 & 3361.3 & 0.848 \\
\hline 6 classes & -10972.3 & 0.938 & 97 & 22138.5 & 22631.9 & 22323.7 & 12269.3 & 3361.3 & 0.832 \\
\hline
\end{tabular}

Note. $\mathrm{LCA}=$ latent class analysis; AIC $=$ Akaike information criterion; BIC = Bayesian information criterion. The fourth class had the best fit across all indices.

Table 3. Second-Order LCA Model of Mother-Father Discipline Behavior.

\begin{tabular}{|c|c|c|c|c|}
\hline Second-Order class (\%) & \multicolumn{2}{|c|}{ Disciplinary behavior } & \multicolumn{2}{|c|}{ Class counts } \\
\hline \multirow{2}{*}{ Class I (45.0) } & MPA & MPA & $421(35.2)$ & $383.0(32.1)$ \\
\hline & MPA & LA & $106(8.9)$ & $97.4(8.2)$ \\
\hline \multirow[t]{2}{*}{ Class 2 (24.3) } & MPA & LD & $90(7.5)$ & 91.7 (7.7) \\
\hline & HPPA & LD & $18(1.5)$ & I5.I (I.3) \\
\hline Class 3 (16.2) & LA & LA & $193(16.2)$ & $207.3(17.3)$ \\
\hline \multirow[t]{2}{*}{ Class 4 (14.6) } & HPPA & MPA & $52(4.4)$ & $43.5(3.6)$ \\
\hline & HPPA & HPPA & $122(10.2)$ & $121.7(10.2)$ \\
\hline
\end{tabular}

Note. $\mathrm{LCA}=$ latent class analysis; $\mathrm{LD}=$ low discipline; $\mathrm{LA}=$ low aggression; $\mathrm{MPA}=$ moderate physical aggression; HPPA $=$ high physical and psychological aggression; Class I [mother(MPA)-father(MPA /LA)]; Class 2 [mother (mixed)-father (LD)]; Class 3 [mother (LA)-father (LA)]; Class 4 [mother (HPPA)-father (HPPA/ MPA)].

Confirming one of this study's hypotheses, the majority of couples $(81.2 \%)$ employed mutually congruent disciplinary behaviors, defined as dyads in which the second-order LCA disciplinary behavior classes were either in the same class (e.g., LD mother and LD father) or in immediately adjoining classes (e.g., LA mother and LD father). Additionally, more fathers than mothers were in the low-aggression classes and fewer fathers than mothers were in the high-aggression classes.

\section{Examination of the Parenting Context}

Results presented in Table 4 indicate that children of Class 4 [mother (HPPA)-father (HPPA/MPA)] parents had the highest levels of aggression and withdrawn behaviors. In contrast, lower discipline Class 2 [mother (mixed)-father (LD)] and Class 3 [mother (LA)-father (LA)] had children with the lowest aggression behaviors. Also, children from Class 1 [mother (MPA)-father (MPA/LA)] and Class 4 were more likely to present aggressive, $\chi^{2}(3, N=1,194)=29.0, p<.001$, and withdrawn behaviors, $\chi^{2}(3, N=1,194)=9.5, p=.023$, above borderline clinical cut points in terms of CBCL scores (Achenbach \& Rescorla, 2000) than children from Class 2 and Class 3. High levels of aggressive discipline were associated with negative neighborhood processes, including lower levels of collective efficacy, and higher levels of social disorganization and community violence. Class 4 mothers had significantly higher levels of parenting stress compared to other classes. However, there were no differences in fathers' parenting stress.

Parental relationship quality was also associated with class membership. Mothers in Class 4 reported significantly lower levels of perceived support from fathers, more frequent arguing with fathers, and lower rating of overall relationship quality when compared to mothers in the other classes. Similarly, fathers in Class 4 reported significantly lower level of perceived support from mothers than those in Class 2, more frequent arguing with mothers than those in Class 1 and 2, and lower rating of overall relationship quality compared to fathers in all other classes. Further, a higher proportion of mothers in Class 4 reported father-to-mother psychological aggression than those in Class 3.

\section{Analysis of Discordant and Concordant Parenting Styles}

We defined concordant parenting dyads as those in which both parents were included in the same first-order class or in the immediately adjoining class (e.g., LD or LA for low aggression and MPA or HPPA for high aggression). This definition resulted in four dyad groupings, as shown in Table 5. There were no couples in which the mother was in a lowaggression class, while the father was in a high-aggression class.

All child behavior problems significantly differed by the four parenting dyad groupings of discordant and concordant 


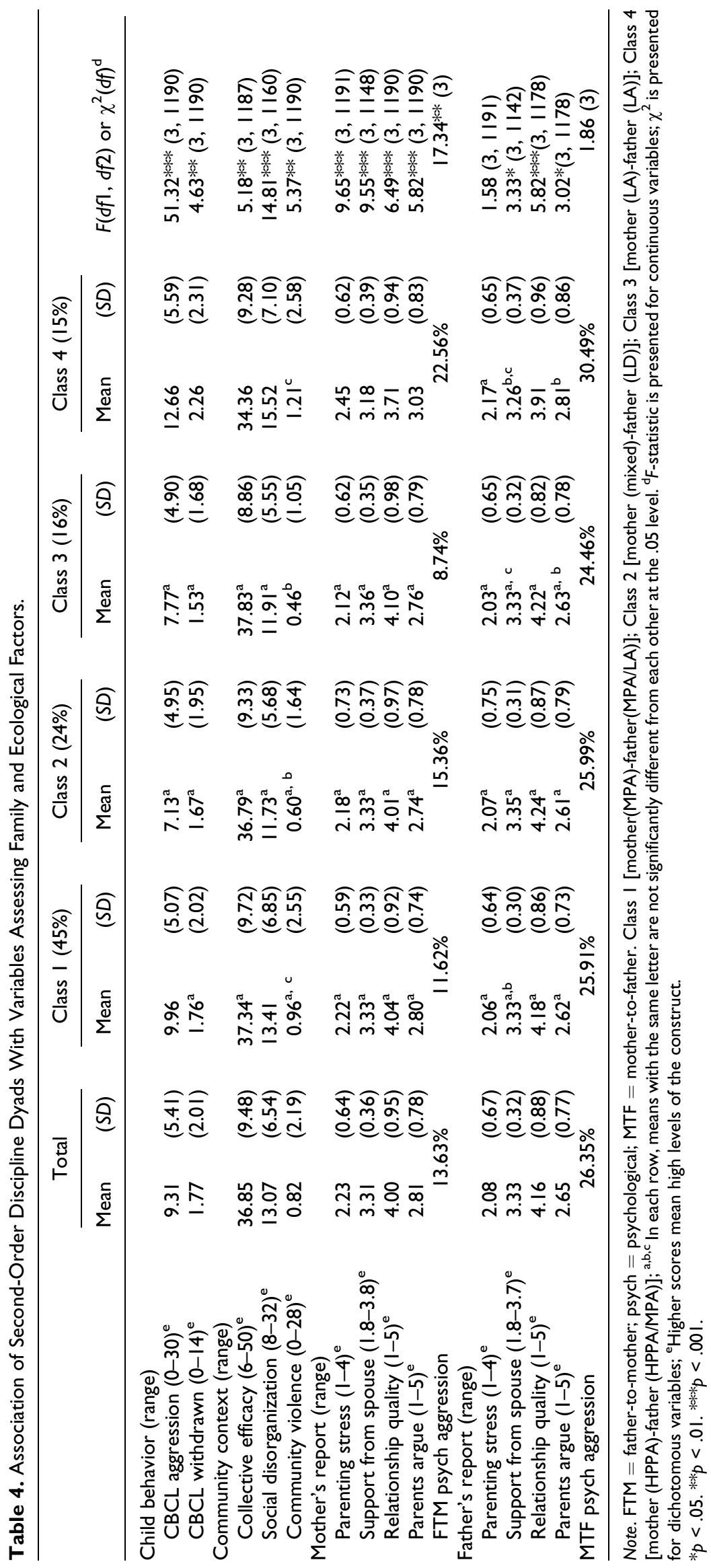


Table 5. Child Behavior Problems and Discipline Dyad Concordance.

\begin{tabular}{|c|c|c|c|c|c|c|c|c|c|c|c|}
\hline CBCL Subscale & \multicolumn{2}{|c|}{ Total } & \multicolumn{2}{|c|}{$\begin{array}{c}\text { Concordant } \\
\text { low agg } \\
(n=375 ; 31 \%)\end{array}$} & \multicolumn{2}{|c|}{$\begin{array}{c}\text { Concordant } \\
\text { high agg } \\
(n=594 ; 50 \%)\end{array}$} & \multicolumn{2}{|c|}{$\begin{array}{c}\text { Discordant MPA } \\
\text { mother } \\
(n=196 ; 16 \%)\end{array}$} & \multicolumn{2}{|c|}{$\begin{array}{c}\text { Discordant HPPA } \\
\text { mother } \\
(n=29 ; 2 \%)\end{array}$} & $F^{c}$ \\
\hline Aggressive (0-30) & 9.31 & $(5.4 I)$ & 6.68 & $(4.7 I)$ & $10.93^{\mathrm{a}}$ & $(5.32)$ & 9.03 & $(4.94)$ & $12.10^{\mathrm{a}}$ & $(4.86)$ & 57.10 **** \\
\hline Withdrawn (0-14) & 1.77 & $(2.01)$ & $1.5 \mathrm{I}^{\mathrm{a}}$ & (1.78) & $1.97^{b}$ & $(2.18)$ & $1.54^{\mathrm{a}, \mathrm{b}}$ & (1.72) & $2.52^{\mathrm{a}, \mathrm{b}}$ & $(2.44)$ & $6.30 * * *$ \\
\hline
\end{tabular}

Note. $\mathrm{CBCL}=$ Child Behavior Checklist; Agg = Aggression. ${ }^{\mathrm{a}, \mathrm{b}}$ In each row, means with the same letter are not significantly different from each other at the .05 level. ${ }^{c}(d f 1, d f 2)=(3, I, 190)$ for all the three comparisons. $* p<.05 . * * p<.01 . * * * p<.001$.

parenting styles (Table 5). Children of concordant lowaggression parents had significantly lower behavior problems scores than all of the other parenting dyad groups. Children of concordant low-aggression parents presented significantly lower withdrawn behavior scores than concordant highaggression parents; however, no differences were found between concordant low-aggression parents and discordant parents on withdrawn behavior. Children of concordant lowaggression parents had significantly lower anxious/depressed behavior problems scores than discordant MPA mother group, discordant HPPA mother dyads, or concordant high-aggression dyads. Further, children of discordant-HPPA mother dyads presented higher level of anxious/depressed behavior problems than the concordant high-aggression dyads.

\section{Discussion}

Although developmental-ecological theory positions the parental relationship as a key element of the family system that may influence maltreatment risk, most studies of discipline do not examine fathers nor do they consider mothers and fathers within couples. We used latent profile analysis of maternal perceptions of both parents' discipline to provide a new perspective on within-couple variation in young children's exposure to a range of parenting behaviors. Our analyses should be considered a first step in examining mothers' and fathers' disciplinary behavior profiles, in part because a limitation of this study is that we rely on mothers' report of fathers' disciplinary behaviors, discussed in detail subsequently. Several key findings emerged.

Consistent with our hypotheses, mothers' reports indicated that mothers' and fathers' disciplinary behavior patterns were similar, but fathers were more likely to be in the lower aggression classes than mothers, and mothers were more likely to be in the high-aggression classes than fathers. A common perception of "traditional" family roles is that of fathers as the primary disciplinarians and mothers as nurturing caregivers. Our study of a large, diverse sample of families provides little evidence that couples today inhabit these gendered roles, at least based on mothers' perceptions of their own and their partners' discipline of young children. The general pattern that mothers engaged in more discipline than do fathers is consistent with studies based on each parents' self-report that show that mothers spank more frequently than do fathers (Day et al., 1998; Straus \& Stewart, 1999). Other studies using observational data or child's report of parents' behaviors have also suggested that parents are either equivalent or mothers do more in the way of disciplining or monitoring children (Barnett, Deng, MillsKoonce, Willoughby, \& Cox, 2008; Simons \& Conger, 1997; Stolz et al., 2005). We extend those findings by showing the same pattern in analyses at the family level and across a wider range of parenting behaviors. These results may be explained in part by the fact that mothers, more so than fathers, assume most of the day-to-day care of young children (Craig, 2006) and therefore have more opportunities to engage in discipline.

Research has shown that negative interactions between one parent-child dyad spillover and contribute to greater use of negative parenting in the other parent-child dyad (Barnett et al., 2008). Research has also shown that mothers who had high levels of aggression toward their children additionally experienced high levels of marital discord (Taylor et al., 2009). Similarly, in this study, higher levels of child behavior problems, more parental stress, poor parental relationship quality, and a perceived community context that is high in violence and low in collective efficacy, were associated with more discipline of young children. Furthermore, rates of male-to-female psychological aggression were high, and mothers who were in the highest aggressive discipline class also reported the highest levels of psychological aggression. These findings are consistent with a basic tenet of the developmental-ecological model that relationships within families are highly interdependent and are also influenced by community contextual factors (Belsky, 1993; Bronfenbrenner, 1979).

We found that, based on mothers' reports of behavior, couples tended to have complementary disciplinary styles. It may be that couples develop similar parenting strategies through mutual influence on each other, a phenomenon that can be understood in terms of assortative mating process (Buss, 1984), in which people tend to marry someone with similar characteristics (Simons \& Conger, 2007). Similar parenting styles adopted by coparenting couples may also result from socialization effects (Buss, 1984), whereby husbands and wives influence and/or adjust to each other and eventually settle on the same parenting approach. Another slightly different 
perspective that is also consistent with the notion of assortative mating is that mothers tend to view their partners as similar to themselves with regard to parenting of young children. The similarity of parents' disciplinary approaches suggests that studies of mothers only may not sufficiently capture the extent of discipline that children are exposed to.

Furthermore, results suggest that additive models that use a sum total of the child's exposure to discipline or average across parents may mask important variations in parental disciplinary approaches (Lee et al., 2011; Martin et al., 2007). Discordant disciplinary styles, in which the mother used high physical and psychological aggression, were associated with significantly higher levels of child aggression than concordant high aggressive parent dyads. This finding is similar to another study that found that adolescent adjustment scores were lowest when both parents were high in authoritarianism or when fathers were permissive and mothers were authoritarian (McKinney \& Renk, 2008). These findings seem to suggest that one parent who is in a low aggressive discipline role may not buffer a child from the potential negative effects of aggressive parenting from their other parent and that discordant parenting approaches may be problematic in a manner similar to dyads in which both parents are high in aggression. Given that there are few prior studies of maltreatment risk of young children that have examined congruency in parental discipline, further study is needed to examine variation and patterns of parental discipline and associations with child well-being and maltreatment.

\section{Study Limitations}

Our analyses were exploratory and descriptive and are suggestive only of associations among variables. We conducted cross-sectional analysis, therefore causal pathways were not examined nor are they inferred. Our sample included only biological parents living in urban areas. Furthermore, it is likely that the study selection criteria of including only married or cohabiting mothers and fathers biased the sample toward more advantaged families (Carlson \& McLanahan, 2010), with parents in such families showing lower levels of depression (Meadows, McLanahan, \& Brooks-Gunn, 2007) and parenting stress (Cooper, McLanahan, Meadows, \& Brooks-Gunn, 2009). Given the community-based sampling approach and the selection of two-parent households, we would expect relatively few children to be in the clinical range for behavior problems. Prior research suggests as much (Sourander \& Helstelä, 2005). For example, one FFCWS study compared children from two-parent households to those from both one-parent and twoparent households and found lower mean levels of child aggression in two-parent households (Lee, Taylor, et al. 2013). As such, results of this study may not be generalizable to single parent households or to families who live in nonurban areas.

As noted earlier, we relied on maternal report of both parents' aggressive discipline as well as child behavior problems and the community context, thus introducing the possibility of measurement bias. This limitation must be considered when interpreting study findings. The results reported herein are consistent with prior research using self-report data from both parents that found that mothers are more likely to spank than fathers (Day et al., 1998; Straus \& Stewart, 1999). Furthermore, one prior study examined mothers' consistency in reporting their spouse or partner's behavior by comparing parents' self-reports of their aggressive parenting to their partners' reports of the same behaviors (Lee, Lansford, Pettit, Dodge, $\&$ Bates, 2012). Mothers were more consistent than fathers in reporting their spouse/partner's behavior. Furthermore, mothers tended to slightly underestimate fathers' use of harsh parenting, suggesting that although mothers' reports were largely consistent with fathers' self-reports, mothers were unaware of all of the instances of fathers' harsh parenting (Lee et al., 2012).

Even if mothers' reports are consistent with fathers' independent reports, the accuracy of self-report data is questionable. Social desirability concerns may have led mothers to underestimate both their own and their partners' aggression. Despite presumed underreporting of parent-to-child aggression with self-report measures, the CTSPC results in rates of maltreatment that are several times higher than rates based on cases known to professionals (Straus et al., 1998). An FFCWS study (Lee, 2013) suggested that parent-reported neglect using the CTSPC was considerably higher than cases detected by child welfare agencies. Furthermore, one recent study found that mothers underreported their use of physical discipline toward their child when compared to observational data collected in the home (Holden, Williamson, \& Holland, In press).

\section{Practice Implications}

These results highlight the importance of targeting both mothers and fathers for parenting support in early childhood. The importance of providing parenting services to both parents has been acknowledged, and although there are relatively few parenting programs designed for fathers (Lundahl, Tollefson, Risser, \& Lovejoy, 2008), progress has been made in developing family-focused interventions. Notable recent efforts include the push to adapt Triple $\mathrm{P}$, an empirically supported child abuse prevention program, for fathers (Fletcher, Freeman, \& Matthey, 2011; Stahlschmidt, Threlfall, Seay, Lewis, \& Kohl, 2013). One challenge - and avenue for future study - is how to effectively sustain fathers' engagement in such programs.

Consistent with our hypotheses, children who experience the most discipline from both parents had high levels of behavioral problems, even in the presence of nonviolent discipline. In fact, use of nonviolent discipline was common among nearly all parents (Straus et al., 1998), even among those with the highest levels of aggressive discipline. This suggests that even parents who use aggressive discipline are aware of alternative approaches such as time-out and redirecting their child. From a strengths-based perspective, interventionists can work with parents to build on these strengths and reinforce the importance of nonaggressive alternatives to physical punishment.

However, the mere presence of nonviolent discipline does not seem sufficient to buffer children from exposure to 
aggression. Indeed, recent research indicates that many parents who use physical punishment, like spanking, also frequently use time-out (Lee et al. 2011) and have high levels of maternal warmth and positive reinforcement (Deater-Deckard et al., 2011; Lee, Altschul, \& Gershoff, 2013). Yet, when examining the differential impact of these parenting approaches (physical discipline vs. warmth and positive reinforcement), longitudinal analyses of the first 5 years of life indicated that positive reinforcement was a consistent predictor of children's social competence, whereas physical punishment was not associated with children's social competence and instead predicted increased child aggression (Lee, Altschul, \& Gershoff, In press). These studies suggest that parents can best reduce their child's risk of developing aggressive behavior through the greater use of positive reinforcement and warmth and the absence of physical discipline, including slapping and spanking children.

A number of promising approaches have recently been developed to provide parents with information about effective discipline. For example, a brief multimedia program delivered to parents in pediatric waiting rooms has been shown to influence parents' intentions to use less physical discipline (Scholer, Hudnut-Beumler, \& Dietrich, 2010). Using a baby book to document a child's development and milestones was associated with less use (by mothers) of physical punishment (Reich, Penner, Duncan, \& Auger, 2012). FaceBook messages (Bartholomew, Schoppe-Sullivan, Glassman, Dush, \& Sullivan, 2012) and text messaging (Carta, Lefever, Bigelow, Borkowski, \& Warren, 2013; Jordan, Ray, Johnson, \& Evans, 2011) may provide a mechanism to reach parents and provide support and guidance regarding age-appropriate child discipline. Although most studies of these approaches focus on mothers, an additional advantage is that messages can be targeted to both mothers and fathers.

\section{Declaration of Conflicting Interests}

The author(s) declared no potential conflicts of interest with respect to the research, authorship, and/or publication of this article.

\section{Funding}

The author(s) disclosed receipt of the following financial support for the research, authorship, and/or publication of this article: The Fragile Families and Child Well-being Study is funded by NICHD grant numbers R01HD36916, R01HD39135, and R01HD40421, as well as a consortium of private foundations and other government agencies.

\section{References}

Abidin, R. (1995). Parent stress inventory (3rd ed.). Odessa, FL: Psychological Assessments Resources.

Achenbach, T. M., \& Rescorla, L. A. (2000). Manual for the ASEBA preschool forms and profiles. Burlington: University of Vermont, Center for Children, Youth \& Families.

Barnett, M. A., Deng, M., Mills-Koonce, W. R., Willoughby, M., \& Cox, M. (2008). Interdependence of parenting of mothers and fathers of infants. Journal of Family Psychology, 22, 561-573.
Bartholomew, M. K., Schoppe-Sullivan, S. J., Glassman, M., Kamp Dush, C. M., \& Sullivan, J. (2012). New parents' Facebook use at the transition to parenthood. Family Relations, 61, 455-469.

Belsky, J. (1993). Etiology of child maltreatment: A developmentalecological analysis. Psychological Bulletin, 114, 413-434.

Bronfenbrenner, U. (1979). The ecology of human development: Experiments by nature and design. Cambridge, MA: Harvard University Press.

Buss, D. M. (1984). Toward a psychology of person-environment (PE) correlation: The role of spouse selection. Journal of Personality and Social Psychology, 47, 361-377.

Carlson, M. J., \& McLanahan, S. S. (2010). Fathers in fragile families. In M. E. Lamb (Ed.), The role of the father in child development (5th ed., pp. 241-269). Hoboken, NJ: John Wiley.

Carta, J. J., Lefever, J. B., Bigelow, K. M., Borkowski, J. G., \& Warren, S. F. (2013). Randomized trial of a cellular-phone enhanced home visitation parenting intervention. Pediatrics, 132, S167-S173.

Coley, R. L., Lewin-Bizan, S., \& Carrano, J. (2011). Does early paternal parenting promote low-income children's long-term cognitive skills? Journal of Family Issues, 32, 1522-1542.

Cooper, C. E., McLanahan, S. S., Meadows, S. O., \& Brooks-Gunn, J. (2009). Family structure transitions and maternal parenting stress. Journal of Marriage and Family, 71, 558-574.

Coulton, C. J., Korbin, J. E., \& Su, M. (1999). Neighborhoods and child maltreatment: A multilevel study. Child Abuse \& Neglect, 23, 1019-1040.

Cox, M. J., \& Paley, B. (1997). Families as systems. Annual Review of Psychology, 48, 243-267.

Craig, L. (2006). Does father care mean fathers share? A comparison of how mothers and fathers in intact families spend time with children. Gender \& Society, 20, 259-281.

Day, R. D., Peterson, G. W., \& McCracken, C. (1998). Predicting spanking of younger and older children by mothers and fathers. Journal of Marriage and the Family, 60, 79-94.

Deater-Deckard, K., Lansford, J. E., Malone, P. S., Alampay, L. P., Sorbring, E., Bacchini, D., ... Al-Hassan, S. M. (2011). The association between parental warmth and control in thirteen cultural groups. Journal of Family Psychology, 25, 790-794.

Fletcher, R., Freeman, E., \& Matthey, S. (2011). The impact of behavioural parent training on fathers' parenting: A meta-analysis of the Triple P-Positive Parenting program. Fathering, 9, 291-312.

Guterman, N. B., Lee, S. J., Taylor, C. A., \& Rathouz, P. J. (2009). Parental perceptions of neighborhood processes, stress, personal control, and risk for physical child abuse and neglect. Child Abuse \& Neglect, 22, 897-906.

Gutman, L. M., McLoyd, V. C., \& Tokoyawa, T. (2008). Financial strain, neighborhood, stress, parenting behaviors, and adolescent adjustment in urban African American families Journal of Research on Adolescence, 154, 425-449.

Holden, G. W., Williamson, P. A., \& Holland, G. W. O. (In press). Eavesdropping on the family: A pilot investigation of corporal punishment in the home. Journal of Family Psychology.

Jewell, J. D., Krohn, E. J., Scott, V. G., Carlton, M., \& Meinz, E. (2008). The differential impact of mothers' and fathers' discipline on preschool children's home and classroom behavior. North American Journal of Psychology, 10, 173-188. 
Jordan, E. T., Ray, E. M., Johnson, P., \& Evans, W. D. (2011). Text4Baby: Using text messaging to improve maternal and newborn health. Nursing for Women's Health, 15, 206-212.

Klein, S., \& Harden, B. J. (2011). Building the evidence-base regarding infants/toddlers in the child welfare system. Children and Youth Services Review, 33, 1333-1336.

Kohen, D. E., Leventhal, T., Dahinten, V. S., \& McIntosh, C. N. (2005). Neighborhood disadvantage: Pathways of effects for young children. Child Development, 79, 156-169.

Lee, S. J. (2013). Paternal and household characteristics associated with child neglect and child protective services involvement. Journal of Social Service Research, 39(2), 171-187.

Lee, S. J., Altschul, I., \& Gershoff, E. T. (2013). Does warmth moderate longitudinal associations between maternal spanking and child aggression in early childhood? Developmental Psychology, 49, 2017-2028.

Lee, S. J, Altschul, I., \& Gershoff, E. T. (In press). Maternal warmth, not spanking, predicts positive child behaviors in the first five years of life. Manuscript submitted for publication.

Lee, S. J., Grogan-Kaylor, A., \& Berger, L. (2014). Parental spanking of 1-year-old children and subsequent Child Protective Services involvement. Child Abuse \& Neglect, 89, 875-883.

Lee, S. J., Kim, J. K., Taylor, C. A., \& Perron, B. E. (2011). Profiles of disciplinary behaviors among biological fathers. Child Maltreatment, 16, 51-62.

Lee, S. J., Lansford, J. E., Pettit, G. S., Bates, J. E., \& Dodge, K. A. (2012). Parental agreement of reporting parent to child aggression using the Conflict Tactics Scales. Child Abuse \& Neglect, 36, 510-518.

Lee, S. J., Taylor, C. A., Altschul, I., \& Rice, J. (2013). Parental spanking and subsequent risk for child aggression in father-involved families of young children. Children and Youth Services Review, 35, 1476-1485.

Lo, Y., Mendell, N. R., \& Rubin, D. B. (2001). Testing the number of components in a normal mixture. Biometrika, 88, 767-778.

Lundahl, B., Tollefson, D., Risser, H., \& Lovejoy, M. C. (2008). A meta-analysis of father involvement in parent training. Research on Social Work Practice, 18, 97-106.

Margolin, G., \& Gordis, E. B. (2003). Co-occurrence between marital aggression and parents' child abuse potential: The impact of cumulative stress. Violence \& Victims, 18, 243-258.

Martin, A., Ryan, R. M., \& Brooks-Gunn, J. (2007). The joint influence of mother and father parenting on child cognitive outcomes at age 5. Early Childhood Research Quarterly, 22, 423-439.

McKinney, C., \& Renk, K. (2008). Differential parenting between mothers and fathers: Implications for late adolescents. Journal of Family Issues, 29, 806-827.

Meadows, S. O., McLanahan, S. S., \& Brooks-Gunn, J. (2007). Parental depression and anxiety and early childhood behavior problems across family types. Journal of Marriage and Family, 69, 1162-1177.

Muthen, B. O. (2001). Latent variable mixture modeling. In G. A. Marcoulides \& R. E. Schumacker (Eds.), New developments and techniques in structural equation modeling. Mahwah, NJ: Lawrence Erlbaum.

Prinzie, P., Onghena, P., \& Hellinckx, W. (2006). A cohort-sequential multivariate latent growth curve analysis of normative $\mathrm{CBCL}$ aggressive and delinquent problem behavior: Associations with harsh discipline and gender. International Journal of Behavioral Development, 30, 444-459.
Reich, S. M., Penner, E. K., Duncan, G. J., \& Auger, A. (2012). Using baby books to change new mothers' attitudes about corporal punishment. Child Abuse \& Neglect, 36, 108-117.

Reichman, N. E., Teitler, J. O., Garfinkel, I., \& McLanahan, S. S. (2001). Fragile families: Sample and design. Children and Youth Services Review, 32, 303-326.

Roesch, S. C., Villodas, M., \& Villodas, F. (2010). Latent class/profile analysis in maltreatment research. Child Abuse and Neglect, 34, 155-160.

Ryan, R. M., Martin, A., \& Brooks-Gunn, J. (2006). Is one good parent good enough? Patterns of mother and father parenting and child cognitive outcomes at 24 and 6 months. Parenting: Science and Practice, 6, 211-228.

Sampson, R. J., Raudenbush, S. W., \& Earls, F. (1997). Neighborhoods and violent crime: A multilevel study of collective efficacy. Science, 277, 918-924.

Scholer, S. J., Hudnut-Beumler, J., \& Dietrich, M. S. (2010). A brief primary care intervention helps parents develop plans to discipline. Pediatrics, 125, e242-e249.

Selner-O'Hagan, M. B., Kindlon, D. J., Buka, S. L., Raudenbush, S. W., \& Earls, F. J. (1998). Assessing exposure to violence in urban youth. Journal of Child Psychology and Psychiatry, 39, 215-224.

Simons, L. G., \& Conger, R. D. (2007). Linking mother-father differences in parenting to a typology of family parenting styles and adolescent outcomes. Journal of Family Issues, 28, 212-241.

Slep, A. M. S., \& O'Leary, S. G. (2007). Multivariate models of mothers' and fathers' aggression toward their children. Journal of Consulting and Clinical Psychology, 75, 739-751.

Sourander, A., \& Helstelä, L. (2005). Childhood predictors of externalizing and internalizing problems in adolescence. European Child \& Adolescent Psychiatry, 14, 415-423.

Stahlschmidt, M. J., Threlfall, J., Seay, K. D., Lewis, E. M., \& Kohl, P. L. (2013). Recruiting fathers to parenting programs: Advice from dads and fatherhood program providers. Children and Youth Services Review, 35, 1734-1741.

Stolz, H. E., Barber, B. K., \& Olsen, J. A. (2005). Toward disentangling fathering and mothering: An assessment of relative importance. Journal of Marriage and Family, 67, 1076-1092.

Straus, M. A. (2004). Scoring the CTS2 and CTSPC. Durham: Family Research Laboratory, University of New Hampshire.

Straus, M. A., Hamby, S. L., Finkelhor, D. W., Moore, D. W., \& Runyan, D. (1998). Identification of child maltreatment with the ParentChild Conflict Tactics Scales: Development and psychometric data for a national sample. Child Abuse and Neglect, 22, 249-270.

Straus, M. A., \& Stewart, J. H. (1999). Corporal punishment by American parents: National data on prevalence, chronicity, severity, and duration, in relation to child and family characteristics. Clinical Child and Family Psychology Review, 2, 55-70.

Sturge-Apple, M. L., Davies, P. T., Martin, M. J., Cicchetti, D., \& Hentges, R. F. (2012). An examination of the impact of harsh parenting contexts on children's adaptation within and evolutionary framework. Developmental Psychology, 48, 791-805.

Taylor, C. A., Guterman, N. B., Lee, S. J., \& Rathouz, P. (2009). Intimate partner violence, maternal stress, nativity, and risk for maternal maltreatment of young children. American Journal of Public Health, 99, 175-183. 
Taylor, C. A., Manganello, J. A., Lee, S. J., \& Rice, J. (2010). Mothers' spanking of 3-year-old children and subsequent risk of children's aggressive behavior. Pediatrics, 125, e1057-e1065.

Thompson, M. S., \& Green, S. B. (2006). Evaluating betweengroup differences in latent variable means. In G. R. Hancock \& R. O. Mueller (Eds.), Structural equation modeling: A second course (pp. 119-169). Greenwich, CT: Information Age Publishing.

Wang, M.-T., \& Kenny, S. (2013). Longitudinal links between fathers' and mothers' harsh verbal discipline and adolescents' conduct problems and depressive symptoms. Child Development, $1-16$.

Weiss, R. L., \& Margolin, G. (1977). Assessment of marital conflict and accord. In A. R. Ciminero, K. D. Calhoun, \& H. E. Adams (Eds.), Handbook of behavioral assessment (pp. 555-602). New York, NY: John Wiley.

Zolotor, A. J., Theodore, A. D., Chang, J. J., Berkoff, M. C., \& Runyan, D. K. (2008). Speak softly-And forget the stick: Corporal punishment and child physical abuse. American Journal of Preventive Medicine, 35, 364-369. 